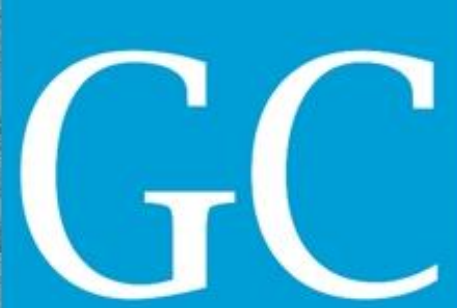

ISSN 2318-8472

Revista Nacional de Gerenciamento de Cidades

\title{
Espaços educativos como medida de recuperação do espaço público
}

Educational spaces as a recovery measure of the public space

Espacios educativos como medida de recuperación del espacio público

\author{
Maria Fernanda Serrano Sartori \\ Mestranda, PPGARQ UNESP/ Campus Bauru \\ fernandassartori@gmail.com
}

\section{Norma Regina Truppel Constantino}

Doutora em Arquitetura e Urbanismo, Professora

assistente Doutora da UNESP/ Campus Bauru norma.rt.constantino@unesp.br 


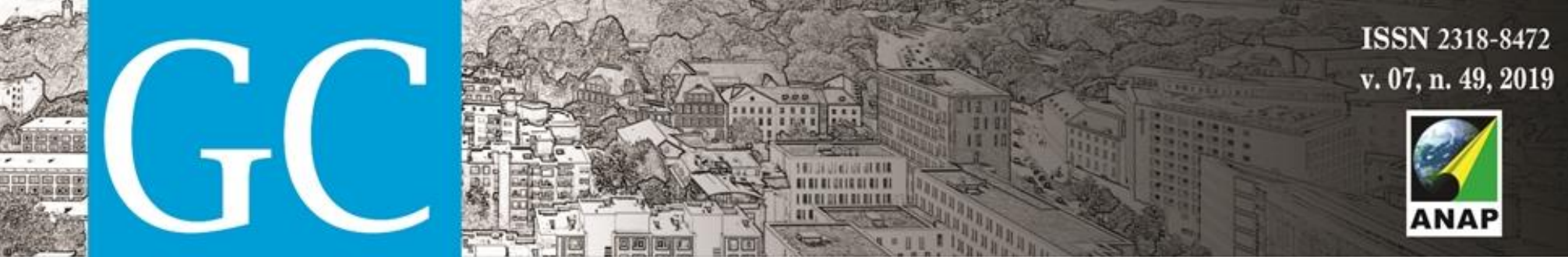

Revista Nacional de Gerenciamento de Cidades

Outro feito foi dar voz aos jovens e crianças através do Conselho das Crianças e Congresso de los Chicos. Trata-se de um modelo participativo em que a população infanto-juvenil é convidada a sugerir ideias para o poder público sobre o que querem que seja feito e que ocorra na cidade. Conforme as palavras de Azevedo e Bastos (2002, p. 156), o envolvimento dos usuários no processo de decisão constitui a única forma de garantir que suas necessidades e seus valores sejam levados em consideração, o que revela a eficiência dessa medida, uma vez que a população passa a se sentir mais responsável pela cidadania.

Além disso, pode-se citar o Programa de Arquitetura Urbana Verde. A partir dele, conseguiu-se criar uma fonte alternativa de renda para a parte mais pobre da população através de hortas comunitárias na periferia de Rosário, em terrenos abandonados ou da prefeitura, como ilustra a figura 3. Técnicas de plantio foram ensinadas aos participantes e a visibilidade do projeto facilitou a regularização de terrenos abandonados como locais para as "hortas urbanas". Segundo Reker (2015), atividades que capacitam os cidadãos para a ação, para serem agentes do espaço público e não observadores ou consumidores passivos, representam uma transformação da relação entre o cidadão e o espaço público.

Figura 3: Programa de Arquitetura Urbana Verde

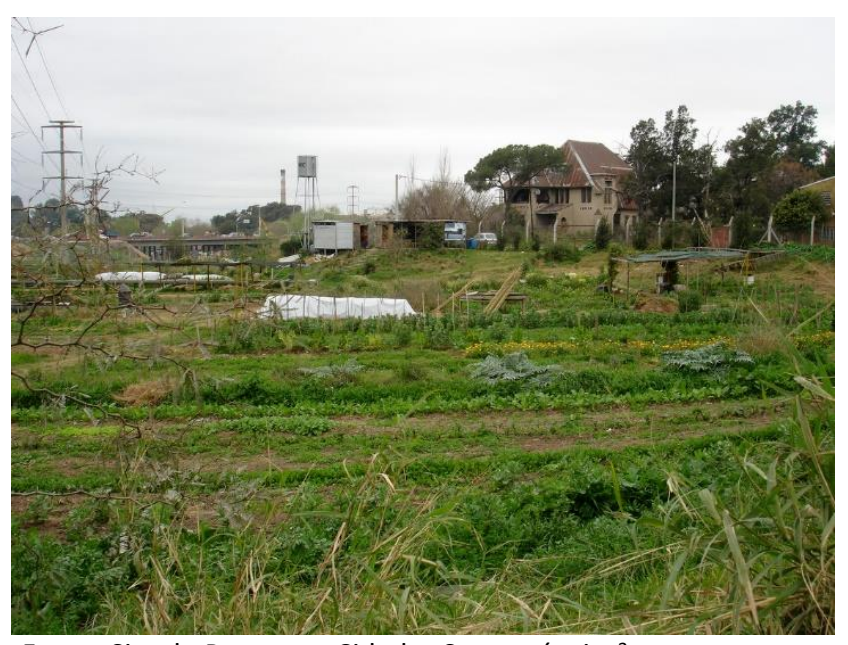

Fonte: Site do Programa Cidades Sustentáveis. ${ }^{3}$

Nesse sentido, Reker (2015) ainda declara que espaços que possibilitam a transformação e a plantação trazem a sensação de responsabilidade àqueles que cuidam, fazendo com que o espaço público deixe de ser um espaço de ninguém para se tornar um espaço de todos.

A cidade de Rosário revela, então, exemplos de como deixar o espaço urbano aos cuidados de seus habitantes pode proporcionar uma experiência sensível de comprometimento e apreciação

\footnotetext{
${ }^{3}$ Disponível em: <https://www.cidadessustentaveis.org.br/boaspraticas/programa-de-agriculturaurbana-verde-0>. Acesso em: 17 mai. 2018
} 

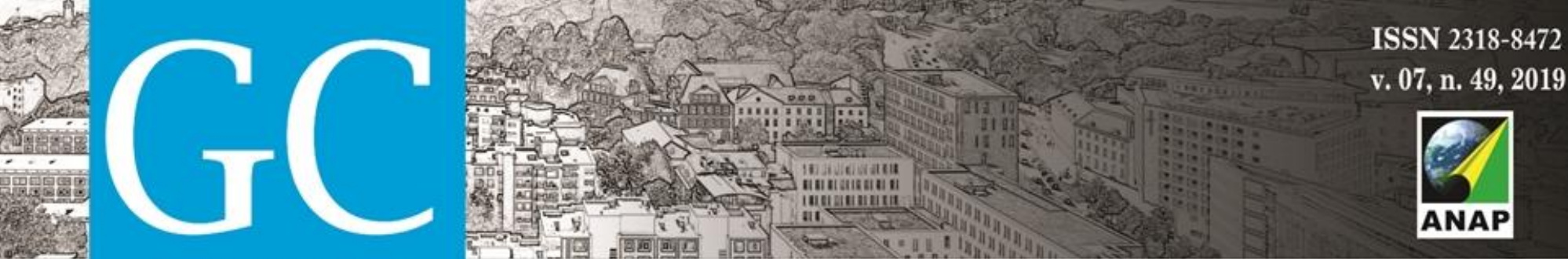

Revista Nacional de

Gerenciamento de Cidades

da cidade. Tais métodos deixam evidente o esforço para conectar a população de volta às áreas públicas urbanas. Através da criação de novos significados e memórias, encontra-se lugar para a sensação de pertencimento e cuidado com os espaços públicos, a partir de espaços lúdicos e educativos, programas participativos e da transformação dos moradores em interventores ativos.

\section{CONSIDERAÇÕES FINAIS}

Pode-se perceber uma série de fatores para o abandono do espaço público, intimamente ligados a impossibilidade de compreensão dos significados presentes na paisagem por parte da população, a qual também não se sente pertencente às áreas públicas da cidade pelo fato de não as utilizar e de não desenvolver experiências sensoriais capazes de produzir sentido. Esse cenário facilita a lógica do mercado imobiliário, que se baseia no consumo e tira proveito da sensação de medo que os espaços públicos não frequentados provocam.

Essa é uma questão a ser cuidada, uma vez que interfere de forma preocupante na paisagem das cidades, cada vez mais envoltas de muros e ocupadas por espaços de consumo interiorizados, em detrimento do espaço público.

O poder público também contribui para o agravamento da situação ao apoiar-se em uma visão padronizada e monofuncional para as áreas públicas urbanas, anulando os valores e necessidades das comunidades que fazem parte do cotidiano desses espaços e dificultando a compreensão dos significados presentes por não terem sido construídos a partir de um processo cultural de qualificação da paisagem.

Como elemento conclusivo, fica evidenciado a importância de um programa com a participação dos usuários do espaço público, pois tem o poder de fazer com que as pessoas se sintam responsáveis por esses espaços, ao identificarem as partes que lhe pertencem de alguma forma. Além disso, o investimento em espaços lúdicos e educativos na cidade também aparece como uma boa solução no sentido de estimular experiências multissensoriais desde a infância, auxiliando na construção da memória e da identidade do espaço público, a fim de que volte a ser utilizado para que possa ser cuidado e para que faça parte do dia a dia da população.

Por fim, a cidade de Rosário aparece como estudo de caso e referência de Cidade Educadora. Esse conceito está relacionado à transformação das cidades em territórios educativos, tornando-as mais justas e incentivando a convivência, solidariedade, igualdade de oportunidades e integração social. Assim, a cidade argentina procura executar ações baseadas na reutilização de espaços ligados à memória da população e no incentivo à participação de crianças e jovens nas decisões da cidade, práticas que se mostraram eficientes na recuperação do espaço público. 
